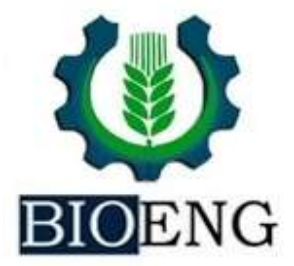

\title{
FONTES E MODOS DE APLICAÇÃO DE NITROGÊNIO NA CULTURA DO MILHO EM SISTEMA PLANTIO DIRETO
}

\author{
F. H. Kaneko ${ }^{1 *}$; O. Arf ${ }^{1}$; M. T. Sabundjian ${ }^{2} ;$ J. P. Ferreira ${ }^{2}$; \\ D.C.Gitti ${ }^{2}$; A.J.F.Leal ${ }^{3}$; V. Nascimento ${ }^{2}$
}

\begin{abstract}
${ }^{1}$ IFMS - Instituto Federal de Mato Grosso do Sul, Laranjal, Nova Andradina, MS, Brasil ${ }^{2}$ UNESP - Univ Estadual Paulista, FEIS - Faculdade de Engenharia de Ilha Solteira, Departamento de Fitotecnia, Tecnologia de Alimentos e Sócio Economia, Ilha Solteira,SP, Brasil

${ }^{3}$ UFMS - Univ Federal de Mato Grosso do Sul, Campus Chapadão do Sul, MS, Brasil
\end{abstract}

Article history: Received 05 June 2015; Received in revised form 18 June 2015; Accepted 29 June 2015; Available online 30 June 2015.

\section{RESUMO}

O milho é uma das culturas mais exigentes em fertilizantes, especialmente os nitrogenados. Com isso o presente trabalho teve como objetivo avaliar, em solo de cerrado, o efeito de fontes e modos de aplicação de nitrogênio $(\mathrm{N})$ com e sem incorporação pela água de irrigação, na cultura do milho em sistema plantio direto. $\mathrm{O}$ experimento foi conduzido em Latossolo vermelho distrófico argiloso. O delineamento experimental foi em blocos casualizados com 12 tratamentos dispostos em esquema fatorial $3 \times 2 \times 2$, com quatro repetições. Os tratamentos foram constituídos por duas fontes de $\mathrm{N}$ (ureia,_nitrato de amônio e testemunha - sem N), dois modos de aplicação (a lanço e em faixas) com ou sem a incorporação pela lâmina dede irrigação de $10 \mathrm{~mm}$. Foram avaliadas: a massa de cem grãos e a produtividade de grãos $\left(\mathrm{kg} \mathrm{ha}^{-1}\right)$. Pode-se concluir que houve efeito da adubação nitrogenada, sendo que nitrato de amônio proporcionou a maior produtividade de grãos. Em relação aos modos de aplicação, quando a adubação foi realizada a lanço obteve-se a maior produtividade de grãos. Já a incorporação do N com lâmina de irrigação de $10 \mathrm{~mm}$, embora tenha influenciado a massa dos grãos, não incrementou a produtividade de grãos de milho.

Palavras-chave: Adubação de cobertura, incorporação, manejo do nitrogênio, Cerrado.

\section{SOURCES OF NITROGEN AND MODES OF APPLICATION IN MAIZE UNDER NO TILLAGE CROP}

\begin{abstract}
Maize is one of the most demanding cultures fertilizers, especially nitrogen. Thus this study aimed to evaluate, in cerrado soil, the effect of $\mathrm{N}$ sources and application methods with and without merger by irrigation water, in maize in no-till system. The experiment was conducted in red Latosol. The experimental design was randomized blocks with 12 treatments in a factorial $3 \times 2 \times 2$, with four replications. Treatments consisted of two $\mathrm{N}$ sources (urea, ammonium nitrate and witness - without $\mathrm{N}$ ), two application methods (broadcasted and banded) with or without incorporating with blade irrigation of $10 \mathrm{~mm}$. were evaluated: the
\end{abstract}

*flavio.kaneko@ifms.edu.br 
mass of one hundred grains and grain yield $\left(\mathrm{kg} \mathrm{ha}^{-1}\right)$. It can be concluded that there was effect of nitrogen fertilization, and ammonium nitrate provided the highest grain yield. Regarding the picture modes when $\mathrm{N}$ fertilizer was applied to haul obtained the highest grain yield. Since the incorporation of the $\mathrm{N}$ irrigation with $10 \mathrm{~mm}$ blade, but it influenced the mass of grains, not increased the grain yield.

Keywords: topdressing, incorporation, nitrogen management, Cerrado

\section{INTRODUÇÃO}

O milho é uma das culturas mais exigentes em nitrogênio, sendo o inadequado fornecimento e os baixos teores no solo um dos fatores limitantes a produtividade (Civardi et al. 2011). Isto porque este elemento exerce importante influência nos processos bioquímicos relacionados ao desenvolvimento das plantas, principalmente das folhas (Schroder et al. 2000).

No sistema solo-planta o $\mathrm{N}$ é encontrando predominantemente nas formas orgânicas, representando $95 \%$ do $\mathrm{N}$ total do solo (Cantarella e Montezano, 2010), sendo que para sua liberação e absorção pelas plantas é necessário que ocorra o processo de mineralização tornando-o disponível nas formas de $\mathrm{NH}_{4}{ }^{+}$ e/ou $\mathrm{NO}_{3}{ }^{-}$(Fornasieri, 2007).

A forma de aplicação do $\mathrm{N}$ pode influenciar o seu aproveitamento pelo milho. A aplicação do $\mathrm{N}$ à lanço sobre a superfície do solo é uma prática comumente utilizada por produtores na região de cerrado, por apresentar facilidade de aplicação e rendimento operacional. Porém pode resultar em grandes perdas de $\mathrm{N}$ por volatilização de amônia, quando fornecido via ureia (Silva et al. 2005) e danos foliares, sendo esse segundo mais frequente quando da adoção de nitrato de amônio como fonte, pelo seu maior poder de salinização. Além disso, é possível que ocorra maior imobilização do $\mathrm{N}$ mineral pelos microrganismos do solo para a

\section{MATERIAL E MÉTODO}

O experimento foi conduzido no ano agrícola de 2008/09 em Selvíria, MS, em área experimental pertencente à Faculdade de Engenharia - UNESP, decomposição dos resíduos orgânicos presentes na superfície do solo (Amado et al. 2002).

O grande desafio no manejo deste nutriente, principalmente quando utilizada a ureia, é aumentar a quantidade absorvida pelas plantas e diminuir, ao mesmo tempo, as perdas ocorridas. A incorporação do fertilizante nitrogenado pela precipitação pluvial e/ou irrigação com lâmina de 10 a $20 \mathrm{~mm}$ podem constituir em importantes mecanismos para minimizar as perdas de nitrogênio amoniacal, pela volatilização (Cantarella e Montezano, 2010; Ferrara et al., 2014).

De acordo com Cantarella \& Montezeno (2010), a ureia é o principal fertilizante sólido no mercado mundial. No Brasil, esse produto responde por cerca de $60 \%$ dos fertilizantes nitrogenados comercializados, havendo uma clara preferência da indústria pela fabricação de ureia, em comparação com outras fontes sólidas de nitrogênio, em função de menor custo e maior facilidade de produção. As fontes sulfato de amônio e nitrato de amônio, no entanto só sofrem perdas por volatilização de $\mathrm{N}$ amoniacal $\left(\mathrm{N}-\mathrm{NH}_{3}\right)$, quando o pH é superior a 7, situação esta, incomum nos solos de regiões tropicais.

O presente trabalho teve como objetivo avaliar o efeito de fontes, modos de aplicação e incorporação do nitrogênio, na cultura do milho em sistema plantio direto, em solo de cerrado.

Campus de Ilha Solteira, situada aproximadamente a $51^{\circ} 22^{\prime}$ de longitude $\mathrm{W}$ e $20^{\circ} 22^{\prime}$ de Latitude $\mathrm{S}$, com altitude de 335 metros. O solo local é do tipo 
Latossolo vermelho distrófico argiloso (Santos et al. 2013). A precipitação média é de $1.370 \mathrm{~mm}$, a temperatura de $23,5^{\circ} \mathrm{C}$ e a umidade relativa do ar entre 70 e $80 \%$ (média anual).

O solo da área experimental apresentava as seguintes características na camada de $0-0,20 \mathrm{~m}: \mathrm{P}$ (resina) $=13 \mathrm{mg}$ $\mathrm{dm}^{-3}$; Matéria orgânica $=17 \mathrm{~g} \mathrm{dm}^{-3} ; \mathrm{pH}$ $\left(\mathrm{CaCl}_{2}\right)=4,8 ; \mathrm{K}, \mathrm{Ca}, \mathrm{Mg}, \mathrm{Al}$ e $\mathrm{H}+\mathrm{Al}=$ 2,$9 ; \quad 24 ; 13 ; 1$ e 46 mmol $_{\mathrm{c}} \mathrm{dm}^{-3}$, respectivamente e $\mathrm{V} \%=46 . \mathrm{O}$ fornecimento de água, quando necessário, foi realizado por aspersão utilizando um pivô central.

O delineamento experimental utilizado foi o de blocos casualizados com 12 tratamentos dispostos em esquema fatorial $3 \times 2 \times 2$ com quatro repetições. Os tratamentos foram constituídos por três fontes de $\mathrm{N}$ (ureia e nitrato de amônio e testemunha - sem N), dois modos de aplicação dos fertilizantes nitrogenadas (à lanço e em faixas) com ou sem incorporação de $\mathrm{N}$ pela irrigação com lâmina de $10 \mathrm{~mm}$.

As parcelas foram constituídas por 7 linhas (espaçamento de $0,85 \mathrm{~m}$ ) de milho com $10 \mathrm{~m}$ de comprimento, considerandose como bordadura as linhas laterais da parcela e mais $1 \mathrm{~m}$ em ambas as extremidades de cada linha. Entre as parcelas foi mantido um espaço livre de 1 m.

Foi realizado o tratamento das sementes de milho com os inseticidas Imidacloprid e tiodicarbe (52,5 g e 157,5 g do i.a. $\mathrm{ha}^{-1}$, respectivamente) visando $\mathrm{o}$ controle de pragas inicias. Em relação ao manejo de lagartas (Spodoptera frugiperda), foram necessárias três aplicação de $215 \mathrm{~g}$ i.a. de metomil.

A semeadura foi realizada no dia 28 de dezembro de 2008 utilizando o híbrido AG 8088 com regulagem de semeadura para obtenção de 60.000 plantas $\mathrm{ha}^{-1}$. A emergência das plântulas ocorreu 7 dias após a semeadura.

A adubação mineral básica nos sulcos de semeadura do milho constou de $300 \mathrm{~kg} \mathrm{ha}^{-1}$ da formulação 08-28-16. A adubação nitrogenada em cobertura consistiu em $90 \mathrm{~kg} \mathrm{ha}^{-1}$ realizada em uma única aplicação quando as plantas apresentavam-se no estádio V6.

O controle de plantas daninhas nos dois experimentos foi realizado em pósemergência, na fase $\mathrm{V}_{3}$ da cultura do milho, com a aplicação de 84 g i.a. de tembrotrione $+1000 \mathrm{~g}$ i.a. de atrazina + 720 g i.a. de ester metílico de óleo de soja (adjuvante).

Foram realizadas as seguintes avaliações: massa de cem grãos e produção de grãos $\left(\mathrm{kg} \mathrm{ha}^{-1}\right)$. Essa segunda foi determinada através da colheita das espigas das plantas de 4 linhas de $8 \mathrm{~m}$ de comprimento, da área útil de cada parcela. Posteriormente os grãos foram pesados e os dados transformados em kg ha ${ }^{-1}(13 \%$ base úmida).

Os dados foram submetidos a análise de variância (Anova) e na presença de significância pelo Teste $\mathrm{F}(\mathrm{p}<0,05)$, as médias foram submetidas ao teste de Tukey a $5 \%$ de probabilidade.

\section{RESULTADOS E DISCUSSÃO}

Os valores obtidos estão apresentados nas Tabelas 1 e 2. As fontes de nitrogênio não influenciaram a massa dos grãos, todavia, houve interação significativa entre os modos de aplicação e a incorporação do $\mathrm{N}$ com lâmina de irrigação, sendo os desdobramentos apresentados na Tabela 2. 
Tabela 1 - Valores médios da massa de cem grãos e produtividade em função da adubação nitrogenada tendo com fontes de $\mathrm{N}$ a ureia e o nitrato de amônio, aplicados a lanço e em faixas, com e sem incorporação em milho cultivado em Selvíria (MS), safra 2008/09.

\begin{tabular}{lcc}
\hline Tratamento & $\begin{array}{c}\text { Massa de cem grãos } \\
(\mathbf{g})\end{array}$ & $\begin{array}{c}\text { Produtividade } \\
\left(\mathbf{k g ~ h a}^{-\mathbf{1}}\right)\end{array}$ \\
\hline Fontes (F) & 29,90 & $5.853 \mathrm{~b}$ \\
Sem N & 31,17 & $6.134 \mathrm{~b}$ \\
Ureia & 31,18 & $6.645 \mathrm{a}$ \\
Nitrato de amônio & & \\
Modos de aplicação (M) & 30,75 & $6.202 \mathrm{~b}$ \\
Faixa & 31,40 & $6.459 \mathrm{a}$ \\
Lanço & & \\
Incorporação (I) & 31,41 & 6.320 \\
Incorporado & 30,95 & 6.459 \\
Superfície & $\mathbf{1 , 7 6}$ & $\mathbf{3 4 0 , 9}$ \\
\hline DMS & $\mathbf{9 , 3 1}$ & $\mathbf{8 , 7 7}$ \\
\hline CV(\%) & & \\
Teste F & 0,01 & $6,60(\mathrm{P}<0,05)$ \\
F & 0,69 & $3,57(\mathrm{P}<0,05)$ \\
M & 0,19 & 0,49 \\
I & 1,42 & 0,07 \\
F x M & 0,11 & 0,05 \\
F x I & $6,83(\mathrm{P}<0,05)$ & 0,18 \\
M x I & 2,16 & 0,05 \\
F x M x I &
\end{tabular}

Médias seguidas de letras diferentes diferem estatisticamente entre si pelo teste de Tukey $5 \%$ de probabilidade. D.M.S.: diferença mínima significativa.

Tabela 2 - Desdobramento da interação entre modos de aplicação e incorporação do N pela lâmina de 10 mm de irrigação para a massa de cem grãos de milho. Selvíria (MS), 2008/09.

\begin{tabular}{lll}
\hline & Massa de cem grãos $(\mathrm{g})$ & \\
\hline Modo de aplicação & Incorporado & Superfície \\
\hline Faixa & $32,31 \mathrm{~A}$ & $29,19 \mathrm{~B}$ \\
Lanço & 30,48 & 32,75 \\
\hline
\end{tabular}

D.M.S: 2,45

Médias seguidas de letras diferentes na mesma linha diferem estatisticamente entre si pelo Teste de Tukey $5 \%$ de probabilidade. D.M.S.: diferença mínima significativa.

A aplicação do $\mathrm{N}$ em faixas quando incorporada pela lâmina de irrigação de 10 $\mathrm{mm}$ propiciou maior massa de cem grãos $(32,31 \mathrm{~g})$, em relação à ausência da incorporação $(29,19$ g). Já quando a aplicação foi feita à lanço, não houve influência da incorporação do $\mathrm{N}$ sobre esta variável, indo ao encontro dos resultados obtidos por Oliveira e Caires (2003) em relação aos modos de aplicação de $\mathrm{N}$ para a massa dos grãos da cultura do milho.
Já em relação a produtividade de grãos, esta foi alterada pelas fontes de nitrogênio e os modos de aplicação das mesmas (Tabela 1). A maior produtividade de grãos foi proporcionada pelo nitrato de amônio $\left(6.645, \mathrm{~kg} \mathrm{ha} \mathrm{ha}^{-1}\right)$ diferindo estatisticamente da ureia $\left(6.133 \mathrm{~kg} \mathrm{ha}^{-1}\right) \mathrm{e}$ da ausência da aplicação de nitrogênio (5.853 kg ha ${ }^{-1}$ ). Em trabalho semelhante Kaneko et al. (2013) obtiveram maiores produtividades, em dois anos agrícolas, quando a fonte nitrato de amônio foi 
utilizada. Isso ocorre porque os grânulos de ureia em contato com o solo proporcionam reações químicas que alcalinizam o meio ao redor de seus grânulos, propiciando perdas por volatilização de amônia, principalmente em aplicações superficiais (Faria et al., 2014; Yi-Hua et al., 2014; Chen et al., 2015). Assim, uma alternativa apontada por Kaneko et al. (2013) para minimizar as perdas de $\mathrm{N}$ pela ureia, é o revestimento da mesma com NBPT (inibidor de urease), que pode ser mais eficiente que a ureia tradicional, em condições ambientais favoráveis a volatilização .

O modo de aplicação à lanço do nitrogênio conferiu a maior produtividade de grãos $\left(6.459 \mathrm{~kg} \mathrm{ha}^{-1}\right)$ em relação a aplicação em faixas ao lado da plantas de milho, que proporcionou a menor produtividade $\left(6.202 \mathrm{~kg} \mathrm{ha}^{-1}\right)$.

\section{CONCLUSÕES}

Houve efeito da adubação nitrogenada, sendo que nitrato de amônio proporcionou a maior produtividade de grãos. Em relação aos modos de aplicação, quando a adubação foi realizada à lanço obteve-se a maior produtividade de grãos.

\section{AGRADECIMENTO}

Os autores agradecem a Fazenda de Ensino, Pesquisa e Extensão da UNESP, Campus de Ilha Solteira, SP, pelo

\section{REFERÊNCIAS BIBLIOGRÁFICAS}

AMADO, T.J.C.; MIELNICZUK, J. \& AITA, C. Recomendação de adubação nitrogenada para o milho no RS e SC adaptada ao uso de culturas de cobertura do solo, sob sistema plantio direto. Revista Brasileira de Ciência do Solo, v. 26, p. 241-248, 2002.

ANDREOTTI, M.; NAVA, I.A.; WIMMER NETO, L.; GUIMARÃES, V.F.; FURLANI JUNIOR, E. Fontes de nitrogênio e modos de adubação em
A incorporação das fontes de nitrogênio através da água de irrigação não influenciou a produtividade de grãos. No entanto Silva et al (2005), avaliando épocas e formas de aplicação de nitrogênio superficial com incorporação mecânica utilizando equipamento apropriado para o SPD, com disco de corte para abertura do sulco e deposição do fertilizante, concluíram que a incorporação do fertilizante na semeadura e aos 15 dias após a emergência da cultura influenciaram positivamente a produtividade de grãos. Dados controversos aos verificados aqui, são relatados também por Andreotti et al. (2005) que verificaram maior produtividade de grãos quando houve incorporação de fontes minerais de $\mathrm{N}$ no estado do Paraná.

Já a incorporação do $\mathrm{N}$ com lâmina de irrigação de $10 \mathrm{~mm}$, embora tenha influenciado a massa dos grãos, não incrementou a produtividade de grãos de milho.

financiamento e apoio do trabalho em campo.

cobertura sobre a produtividade de feijão (Phaseolus vulgaris L.) na "safra das águas". Acta Scientiarum Agronomy, v.27, n.4, p. 595-602, 2005.

CANTARELLA, H.; MONTEZANO, Z. Nitrogênio e Enxofre. In: PROCHNOW, L.I.; CASARIN, V.; STIPP, S.R. Boas Práticas para Uso Eficiente de Fertilizantes: Nutrientes, v.2, Piracicaba, IPNI, 2010, P.4-46. 
CHEN, A.; LEI, B.; HU, W.; LU, Y.; MAO, Y.; DUAN, Z. SHI, Z. Characteristics of ammonia volatilization on rice grown under different nitrogen application rates and its quantitative predictions in Erhai Lake Watershed, China. Nutrient Cycling in Agroecosystems, v. 101, p.139-152, 2015.

CIVARDI, E.A.; SILVEIRA NETO, A.N.; RAGAGNIN, V.A.; GODOY, E.R.; BROD, E. Ureia de liberação lenta aplicada superficialmente e ureia comum incorporada ao solo no rendimento do milho. Pesquisa Agropecuária Tropical, v.41, n.1, p.52-59, 2011.

FARIA, L.A.; NASCIMENTO, C.A.C.; VENTURA, B.P.; FLORIM, G.P.; LUZ P.H.C.; VITTI, G.C. Hygroscopicity and ammonia volatilization losses from nitrogen sources in coated urea. Revista Brasileira de Ciência do Solo, v.38, p.942948, 2014.

FERRARA, R.M.; LOUBET, B.; DECUQ, C.; PALUMBO, A.D.; DI TOMMASIC, P.; MAGLIULO, V.; MASSON, S.; PERSONNE, E.; CELLIER, P.; RANA, G.; Ammonia volatilisation following urea fertilisation in an irrigated sorghum crop in Italy. Agricultural and Forest Meteorology, p. 195-196, 2014.

FORNASIERI FILHO, D. Manual da cultura do milho. Jaboticabal: FUNEP, 2007, 576p.

KANEKO, F.H; LEAL, A.J.F.; ANSELMO, J.L.; BUZETTI, S.; TOSTA, F.S. Fontes e manejos da adubação nitrogenada em algodoeiro. Pesquisa agropecuária tropical, Goiânia, v.43, n.1, p.57-63, 2013.

SANTOS, H. G.; JACOMINE, P. K. T.; ANJOS, L. H. C.; OLIVEIRA, V. A.; LUMBRERAS, J. F.; COELHO, M. R.; ALMEIDA, J. A.; CUNHA, T. J. F.;

OLIVEIRA, J. B. Sistema brasileiro de classificação de solos. 3. ed. rev. e ampl. Brasília, DF: Embrapa, 2013. 353 p.

SCHRODER, J.J. et al. Does the crop or the soil indicate how to save nitrogen in maize production? Reviewing the stage of art. Field Crops Research, Amsterdan, v. 66, n. 1, p. 151-164, 2000.

SILVA, E.C.; BUZETTI, S.; GUIMARÃES, G.L.; LAZARINI, E.; SÁ, M.E. Doses e épocas de aplicação de nitrogênio na cultura do milho em plantio direto sobre Latossolo vermelho. Revista Brasileira de Ciência do Solo, v. 29, p. 353-362, 2005.

OLIVEIRA, J.M.S.; CAIRES, E.F. Adubação nitrogenada em cobertura para o milho cultivado após aveia preta no sistema plantio direto. Acta Scientiarum Agronomy, v. 25, n. 2, p. 351-357, 2003.

YI-HUA, D.; YU-GE, Z.; SHU-LIN, S.; DAN, J.; YING-GANG, W.; Soil ammonia volatilization under different urea combined fertilization treatments. Shengtaixue Zazhi. v. 33, p.2943-2949, 2014. 